Journal of Applied Pharmaceutical Science Vol. 6 (11), pp. 218-222, November, 2016

Available online at http://www.japsonline.com

DOI: 10.7324/JAPS.2016.601134

ISSN 2231-3354 (cc)) BY-NC-SA

\title{
In vitro Inhibitory Activity of Ethyl Acetate Extract of Symbiotic Bacteria Isolated from the Marine Sponge Haliclona fascigera against Multidrug Resistant Organism (MDRO)
}

\author{
Dian Handayani ${ }^{*}$, Murniati Murniati, Rustini Rustini \\ Faculty of Pharmacy, Andalas University, Padang 25163, Indonesia.
}

\section{ARTICLE INFO \\ Article history: \\ Received on: 28/08/2016 \\ Revised on: 16/09/2016 \\ Accepted on: 06/10/2016 \\ Available online: 29/11/2016}

Key words:

Multidrug resistant

organisms (MDRO),

Antibacterial activity,

Symbiotic bacteria,

Haliclona fascigera.

\begin{abstract}
Increased use of antimicrobial irrational human and veterinary medicine causes increasing emergence of antibiotic resistant organisms or multidrug resistant organisms (MDRO). MDRO are common bacteria that have resistance to multiple types of antibiotics. The objective of the study was to determine the presence of antibacterial activity in the 26 ethyl acetate extracts of symbiotic bacteria from the marine sponge Haliclona fascigera against MDRO. The MDRO employed were Vancomycin-resistant Enterococcus sp (VRE), extended-spectrum-beta ( $\beta$ )- lactamase gram-negative organisms (ESBL), Carbapenem resistant Enterobacteriaceae (CRE) and Multi resistant Acinetobacter baumannii (MRAB). The susceptibility of MDRO against the extracts was determined using the disk diffusion method. The zone of inhibition was measured and expressed in millimeters. The results showed that nine ethyl acetat extracts that considered active to VRE and ESBL. The strongest inhibition activity was found in extract of Micrococcus sp.1 (M2R2) with MIC values of $0.625 \%$ against VRE.
\end{abstract}

\section{INTRODUCTION}

Antimicrobial agents or antibiotics are used to prevent, control and reduce the occurrence of the infection. Antibiotics are semi-synthetic or synthetic substances produced by the natural metabolic processes of some microorganisms that can inhibit or destroy other microorganism (Basri \& Nor, 2014). The increasing irrational use of antimicrobials in humans and veterinary medicine has consequently increased the emergence of antibiotic resistant organisms or multidrug resistant organisms (MDRO). People infected MDRO are more likely to have longer and more expensive hospital stays, and may be more likely to die as a result of the infection. When the drug of choice for treating their infection doesn't work, they require treatment with secondor third-choice drugs that may be less effective, more toxic, and

\footnotetext{
* Corresponding Author

Dian Handayani, Faculty of Pharmacy, Andalas University, Padang 25163, Indonesia. Email: dianh_17@yahoo.com
}

more expensive. This means that patients with an antimicrobialresistant infection may suffer more and pay more for treatment. Today MDRO were considered to be one of the major health problem in the world (Baig, et al., 2015). The United States Center for Disease Control and Prevention (CDC) and European Centre for Disease Prevention and Control (ECDC) came up with a consensual surveillance definition for MDRO, which states, "acquired non-susceptibility to at least one agent in three or more antimicrobial categories" (Magiorakos et al, 2012). Recently, bacterial resistance to different antibiotics has raised dramatically leaving physician with few therapeutic options. Methicillin resistant Staphylococcus aureus (MRSA), extended-spectrum- $\beta$ lactamases (ESBL) producing enterobacteria and vancomycin resistant enterococci (VRE) have become common hospital problems. Study of Mwanri and AlSaleh (2014) showed that from 758 organisms were isolated in Intensive Care Unit Of King Fahad Hofuf Hospital, Saudi Arabia, 90\% of which were gram negative, and $10 \%$ were gram positive. While half of the patients had one organism, the other half had multiple organisms. 
The most frequent type of isolated organisms was Acinetobacter species (29.3\%), Pseudomonas aeruginosa (21.6\%), Klebsiella pneumonia (7\%), ESBL producing Klebsiella pneumonia (6.7\%), and Methicillin Resistant Staphylococcal aureus (MRSA) 5\%.

Marine sponges have been the focus of many studies as they have proved to be a rich source of biologically active secondary metabolites (Edrada, et al., 2000). These compounds may serve as a defense strategy to escape from predators, thus playing a crucial role in sponge survival in the marine ecosystem. Since the discovery of spongothymidine and spongouridine in the early 50's, a great number of biologically active compounds were isolated from marine sponges and their associated microorganisms (Graca, et al., 2015). This continuous study is one of the efforts in exploring marine natural resources in the search for new antibiotic compounds at once an inventory of antibiotic activity derived from microbial symbioses with marine sponge derived from West Sumatra, Indonesia (Handayani, et al. 2015a; Handayani, et al. 2015b, Handayani, et al. 2016).

\section{MATERIAL AND METHODS}

\section{Sponge material, isolation and cultivation of bacteria associated with marine sponge}

Samples sponge that is used and the stages of the research method for isolation and cultivation of symbiotic bacteria have been carried out as it was written in previous studies (Handayani, et al. 2015).

\section{Antibiotic Susceptibility Test}

The pathogenic bacteria Vancomycin resistant Enterococci spp (VRE), extended spectrum beta $(\beta)$ lactamase gram-negative organisms (ESBL), Carbapenem resistant enterobacteriaceae (CRE) and Multi resistant Acinetobacter baumannii (MRAB) were provided by the Laboratory of Microbiology, Public Hospital of M. Djamil Padang, West Sumatra, Indonesia. Antibiotic susceptibility of the MDRO was determined by disk diffusion technique using a commercially available disc (Oxoid ${ }^{\circledR}$-CLSI, 2012). The antimicrobial sensitivity of the test strains to thirteen antibacterial drugs was done using the Kirby Bauer disk diffusion method (Bauer et al., 1966). The antibiotic disks used were ceftazidime $30 \mu \mathrm{g}$, cefotaxime $30 \mu \mathrm{g}$, ceftriaxone $30 \mu \mathrm{g}$, cefoperazone $30 \mu \mathrm{g}$, ciprofloxacin $5 \mu \mathrm{g}$, levofloxacin $5 \mu \mathrm{g}$, ofloxacin $5 \mu \mathrm{g}$, gentamycin $10 \mu \mathrm{g}$, amikacin 30 $\mu \mathrm{g}$, piperacillin $100 \mu \mathrm{g}$, ticarcillin $75 \mu \mathrm{g}$, meropenem $10 \mu \mathrm{g}$, and imipenem $10 \mu \mathrm{g}$. The sterile nutrient agar poured into the plates. Further, $0.1 \mathrm{ml}$ bacterial suspension was spread onto $20 \mathrm{ml}$ of sterile agar plates by using a sterile cotton bud. The plates were allowed to dry before applying antibiotic disc. Then, some commercially available antibiotic discs were gently and firmly placed on the agar plates, which were then left at room temperature for 1 hour to allow diffusion of the antibiotics into the agar medium. The plates were then incubated at $37^{\circ} \mathrm{C}$ for 24 hours. If an antimicrobial activity was present on the plates, it was indicated by an inhibition zone. The diameter of the inhibition zones was measured in millimeter at 24 hours using a scale. The zones of inhibition were measured and the organisms identified as sensitive or resistant based on standard criteria. ESBL production was detected by double disc synergy test. Synergy was determined between a disc of ceftazidime clavulanic acid and a disc of each third generation cephalosporin test antibiotic placed $15 \mathrm{~mm}$ apart on lawn culture of the isolate under test on Mueller Hinton agar plates. The test organism was considered to produce ESBL if the zone size around the antibiotic disc increased towards the ceftazidime clavulanic acid disc. The increase occurs as the clavulanic acid present in the ceftazidime clavulanic acid disc inactivates the ESBL produced by the test organism (Shaikh, et al., 2015).

\section{Antibacterial Assay by Disc Diffusion Method}

The disc diffusion assays were used with some modification to determine the antibacterial effect of ethyl acetate extracts of symbiotic bacteria against MDRO. Muller Hinton Agar (MHA) (Merck, Germany) was used to prepare the culture medium and autoclaved at $121^{\circ} \mathrm{C}$ for $15 \mathrm{~min}$. Briefly, plates (14$\mathrm{cm}$ diameter) were prepared with $14 \mathrm{ml}$ MHA inoculated with 0.1 $\mathrm{ml}$ of bacterial suspension ( $0.1 \mathrm{ml}$ of $0.5 \mathrm{McFarland}$ Standard). The extracts were dissolved in dimethyl sulfoxide (DMSO, 15 $\mu \mathrm{L})$.

Sterile paper discs (6 $\mathrm{mm}$ in diameter) were impregnated

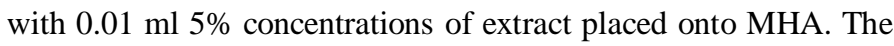
plates were incubated at $37^{\circ} \mathrm{C}$ overnight. Negative controls were prepared using the same solvent employed to dissolve the bacteria extract. Chloramphenicol 0.3\%, Amikacin $30 \mu \mathrm{g}$, Ciprofloxacin 5 $\mu \mathrm{g}$ and Gentamycin $10 \mu \mathrm{g}$ antibiotic disc were tested in the same conditions as positive controls. Inhibition zones in $\mathrm{mm}$ (included disc paper diameter) around discs were measured. The antibacterial activity was expressed as the diameter of inhibition zones produced by the extract against test microorganisms. The experiment was repeated in duplicate and the mean of diameter of the inhibition zones was calculated.

\section{Determination of Minimum Inhibitory Concentration}

The ethyl acetate extracts of symbiotic bacteria that showed greatest diameter of inhibition zone were screened to determine minimum inhibitory concentrations (MIC) by agar diffusion method. The concentration of extract were $5 \%, 2.5 \%$, $1.25 \%$ and $0.625 \%$. MIC was calculated as the lowest concentration of the extract inhibiting the visible growth of bacterial strain.

\section{Identification of Isolates}

Nine extracts of bacterial symbionts which showed high level of inhibition zone against MDRO were selected for further characterization and identification based on macroscopic and microscopic evaluation, gram staining, and biochemical assay to investigate the genus. All bacteriological isolates were examined and confirmed by biochemical tests according to Cowan 
and Steel's Manual of Identification of Medical Bacterial Third Edition (1993).

\section{RESULTS AND DISCUSSION}

MDRO used in this study has been conducted resistance test to some antibiotics. The test was important to prove that the bacteria used is MDRO. The test results of bacterial resistance of VRE, CRE, and MRAB showed sensitive only to the antibiotic fosfomycin and ciprofloxacin. ESBL- Pseudomonas aeruginosa showed resistant to all antibiotics.

The ethyl acetate extracts of bacterial symbionts were tested its bioactivity against microbial pathogens MDRO by agar diffusion method. Antibacterial activity test is done using a $5 \%$ concentration of the extract in dimethylsulfoxide (DMSO). The antibacterial activity of the extracts was assessed from the results of measurements of clear area is formed. Clear area that formed was measured with calipers to the accuracy of $0.05 \mathrm{~mm}$

Based on the test results of the antimicrobial activity of the extract 26 bacterial isolates in Table 1, nine isolates showed growth inhibitory activity against MDRO. The extracts are M2R2, NF1, H2N1, H2N, M1R1, HN1, H1N2, NM2, and M1R2 with inhibition zones $>10 \mathrm{~mm}$ against VRE, CRE and ESBL. But none extracts can inhibit the growth of MRAB.

Table 1: Antibacterial activity of ethyl acetate extracts of symbiotic bacteria from marine sponge $H$. fascigera against MDRO.

\begin{tabular}{|c|c|c|c|c|c|}
\hline \multirow[t]{2}{*}{ No } & \multirow{2}{*}{$\begin{array}{l}\text { Code of } \\
\text { Bacteria }\end{array}$} & \multicolumn{4}{|c|}{$\begin{array}{c}\text { Diameter of the inhibition zone } \pm \text { standard } \\
\text { deviation }\end{array}$} \\
\hline & & VRE & CRE & MRAB & ESBL \\
\hline 1 & $\mathrm{~N} 2 \mathrm{M}$ & $6.50 \pm 0.71$ & $9.25 \pm 1.06$ & - & $9.00 \pm 1.41$ \\
\hline 2 & $\mathrm{~N} 1 \mathrm{~F} 2$ & - & $7.18 \pm 1.17$ & - & $7.50 \pm 0.71$ \\
\hline 3 & $\mathrm{~N} 2 \mathrm{~F} 1$ & $7.50 \pm 2.12$ & $6.73 \pm 1.03$ & - & $8.00 \pm 0.00$ \\
\hline 4 & $\mathrm{NF} 2$ & - & $8.88 \pm 0.53$ & - & $7.50 \pm 0.71$ \\
\hline 5 & HN1 & - & $8.50 \pm 0.71$ & - & $10.00 \pm 1.41$ \\
\hline 6 & $\mathrm{H} 1 \mathrm{~N} 1$ & $6.50 \pm 0.71$ & $8.68 \pm 0.46$ & - & $7.00 \pm 0.00$ \\
\hline 7 & NM2 & $10.63 \pm 0.88$ & $7.05 \pm 0.64$ & - & $8.00 \pm 0.00$ \\
\hline 8 & N2M1 & $7.00 \pm 1.41$ & $8.10 \pm 1.56$ & - & $8.00 \pm 0.00$ \\
\hline 9 & N1M2 & - & $8.05 \pm 0.07$ & - & $7.50 \pm 0.71$ \\
\hline 10 & N1F1 & - & $8.30 \pm 0.28$ & - & $6.50 \pm 0.71$ \\
\hline 11 & $\mathrm{~N} 2 \mathrm{~F}$ & $9.00 \pm 1.41$ & $8.00 \pm 0.00$ & - & $6.50 \pm 0.71$ \\
\hline 12 & $\mathrm{H} 2 \mathrm{~N} 1$ & $11.65 \pm 0.92$ & $7.88 \pm 0.18$ & - & $7.50 \pm 0.71$ \\
\hline 13 & $\mathrm{HN} 2$ & $6.50 \pm 0.71$ & $7.23 \pm 0.11$ & - & $9.00 \pm 0.00$ \\
\hline 14 & $\mathrm{H} 2 \mathrm{~N} 2$ & $6.25 \pm 0.35$ & $7.10 \pm 0.14$ & - & $9.50 \pm 0.71$ \\
\hline 15 & NM1 & $8.00 \pm 1.41$ & $8.00 \pm 0.00$ & - & $7.00 \pm 0.00$ \\
\hline 16 & $\mathrm{~N} 2 \mathrm{M} 2$ & - & $7.83 \pm 0.95$ & - & - \\
\hline 17 & N1M1 & - & $7.63 \pm 0.53$ & - & $8.00 \pm 0.00$ \\
\hline 18 & M2R2 & $21.50 \pm 0.71$ & $7.68 \pm 0.95$ & - & $11.50 \pm 0.71$ \\
\hline 19 & MR2 & $9.83 \pm 0.60$ & $8.33 \pm 0.11$ & - & $8.00 \pm 1.41$ \\
\hline 20 & M1R1 & $10.75 \pm 0.35$ & $8.00 \pm 1.06$ & - & $10.50 \pm 0.71$ \\
\hline 21 & $\mathrm{H} 1 \mathrm{~N} 2$ & $10.38 \pm 0.53$ & $7.75 \pm 0.35$ & - & $10.00 \pm 1.41$ \\
\hline 22 & MR1 & - & $8.00 \pm 1.41$ & - & $9.50 \pm 2.12$ \\
\hline 23 & $\mathrm{H} 2 \mathrm{~N}$ & $10.00 \pm 1.41$ & $8.73 \pm 1.80$ & - & $7.50 \pm 0.71$ \\
\hline 24 & M2R1 & - & $6.75 \pm 1.06$ & - & $7.50 \pm 0.71$ \\
\hline 25 & M1R2 & - & $6.18 \pm 0.25$ & - & $12.00 \pm 0.00$ \\
\hline 26 & NF1 & - & $6.80 \pm 0.28$ & - & $11.50 \pm 0.71$ \\
\hline
\end{tabular}

Arora \& Bhardwaj (1997) has stated that the antibacterial activity can be classified based on the level of sensitivity according to the size of diameter of inhibitory zone without reducing the diameter of the paper disk. High sensitivity is obtained if the diameter of inhibition zone reached > $12 \mathrm{~mm}$.
Intermediate sensitivity category declared if the diameter of the zone is approximately $9-12 \mathrm{~mm}$. Category low sensitivity when the diameter of the zone is 7-9 $\mathrm{mm}$ and resistant if $\leq 6 \mathrm{~mm}$. The greatest activity of extract was found on bacteria code of $M_{2} R_{2}$ against VRE that classified a high sensitivity level with the diameter inhibition zone of $21.50 \pm 0.71 \mathrm{~mm}$ (Fig. 1).

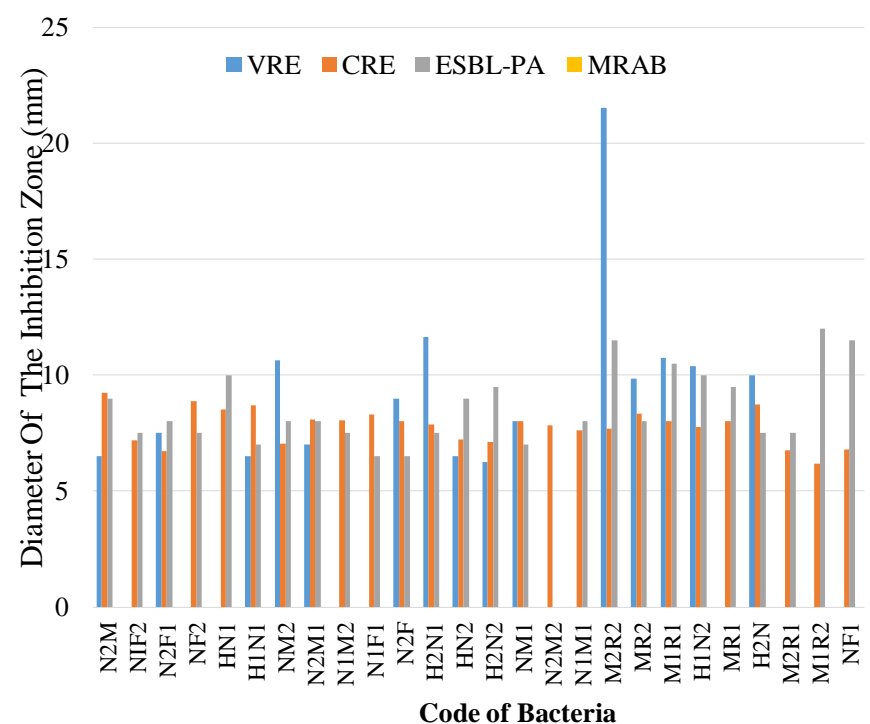

Fig. 1: Antibacterial activity of ethyl acetat extract of symbiotic bacteria against MDRO.

The Extract with the highest antibacterial activity is then determined the Minimum Inhibitory Concentration (MIC) by the method of diffusion agar. MIC determination is done by using multiple concentrations of $5 \% ; 2.5 \% ; 1.25 \%$; and $0.625 \%$. The test results showed inhibition zones of $18.5 \pm 0.35 \mathrm{~mm} ; 10.1 \pm 1.07$ $\mathrm{mm} ; 8: 25 \pm 0: 18 \mathrm{~mm}$; and $6.125 \pm 0.09 \mathrm{~mm}$, respectively (Table 2).

Table 2: Antibacterial activity of ethyl acetate extract of symbiotic bacteria $\mathrm{M}_{2} \mathrm{R}_{2}$ againts Vancomysin Resistant Enterococcus faecalis (VRE) in different concentration.

\begin{tabular}{|c|c|c|c|}
\hline \multirow{2}{*}{ Concentration } & \multicolumn{2}{|c|}{$\begin{array}{c}\text { Diameter of Inhibition Zone } \\
(\mathbf{m m})\end{array}$} & \multirow{2}{*}{$\begin{array}{c}\text { Mean of } \\
\text { Inhibition Zone } \pm \\
\text { Standard } \\
\text { Deviation } \\
\end{array}$} \\
\hline & Paper Disk 1 & Paper Disk 2 & \\
\hline $5.00 \%$ & 18 & 19 & $18.5 \pm 0.35$ \\
\hline $2.50 \%$ & 10 & 10.2 & $10.1 \pm 1.07$ \\
\hline $1.25 \%$ & 8 & 8.5 & $8.25 \pm 0.18$ \\
\hline $0.63 \%$ & 6 & 6.25 & $6.125 \pm 0.09$ \\
\hline
\end{tabular}

It showed that the lowest concentration of bacterial extract $\mathrm{M}_{2} \mathrm{R}_{2}$ that still give the antibacterial activity was $0.625 \%$ (Fig. 2). Nine isolates bacterial symbionts that have antibacterial activity against MDRO were identified by examination of morphological characters macroscopically and microscopically, gram staining and biochemical tests to determine the bacterial genus. Identification of the bacteria refers to a book Cowan and Steel Manual of Medical bacterial identification Third Edition (1993). Biochemical test was done to determine the type or genus of bacteria isolates associated with sponge of $H$. fascigera. 


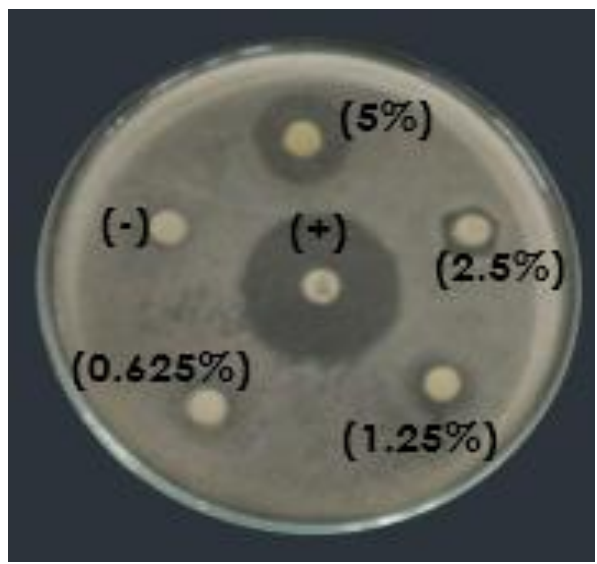

Fig. 2: Antibacterial activity of ethyl acetat extract of symbiotic bacteria $\mathrm{MR}_{2}$ against Vancomysin Resistant Enterococcus faecalis (VRE).

Table 3: Morphological and biochemical characterization for the identification of the selected marine bacterialstrains.

\begin{tabular}{|c|c|c|c|c|c|c|c|c|c|c|c|c|c|c|c|c|c|c|c|c|}
\hline $\begin{array}{l}\text { Code of } \\
\text { Bacteria }\end{array}$ & 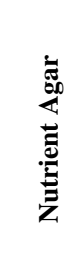 & $\begin{array}{l}\vec{\Xi} \\
\frac{0}{0} \\
\frac{0}{0} \\
\frac{0}{0}\end{array}$ & & & 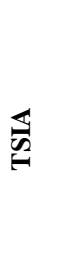 & కే & $\stackrel{\infty}{\mathbb{N}}$ & 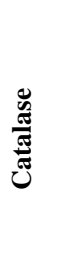 & 苞 & 常 & E & 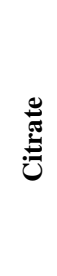 & 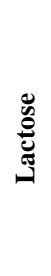 & 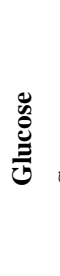 & 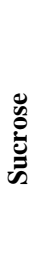 & 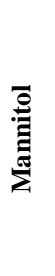 & 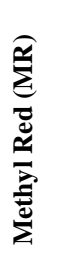 & 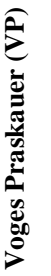 & 0 & Identity \\
\hline $\mathrm{M}_{2} \mathrm{R}_{2}$ & + & YellowCoccus & + & $\mathrm{Y} / \mathrm{y}$ & & - & - & + & - & - & - & - & - & - & & - & - & - & & Micrococcus sp.1 \\
\hline $\mathrm{NF}_{1}$ & + & YellowCoccus & + & $\mathrm{Y} / \mathrm{y}$ & & - & - & $+\quad-$ & - & - & - & - & - & - & - & - & - & - & & Micrococcus sp. 2 \\
\hline $\mathrm{H}_{2} \mathrm{~N}_{1}$ & + & YellowBasil & + & Y/y & & - & - & - & - & - & - & - & - & + & + & + & - & - & & Bacillus sp.1 \\
\hline $\mathrm{H}_{2} \mathrm{~N}$ & + & YellowBasil & + & $\mathrm{Y} / \mathrm{y}$ & & - & - & - & - & - & - & - & - & $+t$ & + & + & - & - & & Bacillus sp.2 \\
\hline $\mathrm{M}_{1} \mathrm{R}_{1}$ & + & YellowBasil & + & $\mathrm{Y} / \mathrm{y}$ & & - & - & - & - & - & - & - & - & ++ & + & + & - & - & & Bacillus sp.3 \\
\hline $\mathrm{HN}_{1}$ & + & YellowBasil & + & Y/y & & - & - & - & - & - & - & - & - & + & + & + & - & 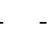 & & Bacillus sp.4 \\
\hline $\mathrm{H}_{1} \mathrm{~N}_{2}$ & + & YellowLong Basil & + & $\mathrm{Y} / \mathrm{y}$ & & - & - & - & + & - & - & - & - & - & - & - & - & - & & Corynebacterium sp.1 \\
\hline $\mathrm{NM}_{2}$ & + & YellowLong Basil & + & Y/y & & - & - & - & $+\quad-$ & - & - & - & - & - & - & - & - & - & & Corynebacterium sp.2 \\
\hline $\mathrm{M}_{1} \mathrm{R}_{2}$ & + & WhiteCoccus & + & Y/y & & - & - & - & + & - & - & - & - & - & - & - & $+t$ & + & & Staphylococcus aureus \\
\hline
\end{tabular}

These tests are used because there are some bacteria that have special properties when reacted with certain biochemical test that can be the specificity or specific genus. Some biochemical tests were conducted as TSIA (Triple Sugar Iron Agar), gas, H2S, catalase, oxidase, mortility, IMViC (Indole, Methyl Red-Voges Proskauer/MR-VP, Citrate), urea, lactose, glucose, sucrose, mannitol, nitrate and gelatin.

The results show that the identification of the four genera classified as Bacillus sp. hereinafter coded as Bacillus sp 1, Bacillus sp 2, Bacillus sp 3 and Bacillus sp 4, two bacteria as Corynebacterium sp 1 and Corynebacterium sp 2. Other two bacteria classified as Micrococcus sp.1 and Micrococcus sp 2 and one other bacteria as Staphylococcus aureus (Table 3). It has been reported that microorganisms play a role in the biological life of the sponge as they are associated with a lot of sponge in the intracellular and extracellular or both. Around $40 \%$ of sponge biomass is thought to contain bacterial community. Some studies have shown that the symbiont has a role in production of bioactive compounds that function in ecological adaptation sponge (Sfanos et al., 2005; Proksch, et al., 2003). Based on the research result, it has been proven that the marine sponge $H$ fascigera containing a large amount diverse of bacteria and fungi. The results of antibacterial bioactivity screening of extracts of microorganisms have proved that they are capable of producing secondary metabolites that are needed to overcome the problem of the treatment of a resistant bacterial infection as MDRO.

\section{CONCLUSIONS}

Infectious disease caused by MDRO was a growing problem in healthcare. Such infections are lead to patients should be treated longer thus resulting increase of medical expenses in the hospital. Therefore, effort is needed in the discovery of new antibiotics to overcome the MDRO.

From the results of this research, 26 symbiotic bacteria from marine sponge $H$. fascigera were isolated. 9 isolates of which can inhibit the growth of VRE, CRE and ESBL. It could also be concluded from this study that the symbiotic bacteria can be used as an important alternative to produce new antibiotics needed in overcome the infection caused by MDRO. 


\section{ACKNOWLEDGEMENT}

The authors are also grateful to the authorities of Laboratory of Microbiology, Public Hospital of M. Djamil Padang, Indonesia for providing us the MDRO culture.

Financial support and sponsorship: This research was funded by Directorate General of Higher Education Ministry of National Education, Indonesia, in project "International Research Collaboration and Publication, No: 07/H.16/KLN/LPPM 2016.

Conflict of Interests: There are no conflicts of interest.

\section{REFERENCES}

Arora DS, Bhardwaj SK. Antibacterial activity of tea against some plants pathogens, Geobios. 1997; 24:127-131.

Basri DF, Nor HHM. Phytoconstituent Screening and Antibacterial Activity of the Leaf Extracts from Canarium odontophyllum Miq. American Journal of Plant Sciences, 2014; 5: 2878-2888.

Baig K, Din SMS, Elkhizzi NA, and AlNakhli DJ. Incidence of Hospital Acquired Multidrug Resistant Organisms in a Tertiary Care Facility. J Infect Dis Epidemiol, 2015; 1:1.

Bauer AW, Kirby WAM, Sherris JS and Turk M. Antibiotic Susceptibility Testing by a Standardized Single Disc Method. The American Journal of Pathology, 1966; 45: 393-396.

Center of Disease Control and Prevention.. AntimicrobialResistant Pathogens Associated With Healthcare- Associated Infections: Annual Summary of Data Reported to the National Healthcare Safety Network at the Centers of Disease Control and Prevention, 2006-2007. Infection Control and Hospital Epidemiology, 2008; 29:11.

Clinical Laboratory Standards Institute. Performance standards for antimicrobial disk susceptibility tests: Approved standard-eleventh Edition. 2012; CLSI Document M02-A11.

Cowan ST, Barrow GI, Steel KJ, and Feltham RKA. Cowan and steel's manual for the identification of medical bacteria. (3rd ed.). 1993; Cambridge: Cambridge University Press.

Edrada RA, Wray V, Handayani D, Schupp P, Balbin-Oliveros M, and Proksch, P. Structure-activity relationships of bioactive metabolites from some Indo-Pacific marine invertebrates. Studies in Natural Products Chemistry 21(B). 2000; 251-292. ISSN 1572-5995

Graca AP, Viana F, Bondoso J, Correia MI, Gomes L, Humanes M, Reis A, Xavier JR, Gaspar H, and Lage OM. The antimicrobial activity of heterotrophic bacteria isolated from the marine sponge Erylus deficiens (Astrophorida, Geodiidae). Wulfenia Journal, 2015; 21 (4).

Handayani D, Sandrawaty N, Murniati M, and Regina R. Screening of Endophytic Bacteria Isolated from Marine Sponge Haliclona fascigera for Inhibition against Clinical Isolates of Methicillin Resistant Staphylococcus aureus (MRSA). Journal of Applied Pharmaceutical Science, 2015a; 5(9): 139-142.
Handayani D, Ahdinur, RF, and Rustini R. Antimicrobial Activity of Endophytic Fungi from Marine Sponge Haliclona fascigera. Journal of Applied Pharm. Science 2015b; 5(10), 154-156

Handayani D, Ornando R and Rustini, Antimicrobial Activity Screening of Symbiotic Fungi from Marine Sponge Petrosia nigrans collected from South Coast of West Sumatera Indonesia, International Journal of Pharmacognosy and Phtochemical research, 2016; 8(4): 623625 .

Magiorakos AP, Srinivasan A, Carey RB, Carmeli Y, Falagas ME, Giske CG, Harbarth S, Hindler JF, Kahlmeter G, Olsson-Liljequist B, Paterson DL, Rice LB, Stelling J, Struelens MJ, Vatopoulus A, Weber JT and Monnet DL. Multidrug-resistant, extensively drug-resistant anf pandrug-resistant bacteria: an international expert proposal for interim standard definition for acquired resistance. Clin Microbiol Infect. 2012; 18: 268-281

Mwanri L, AlSaleh E. Multi-Drug Resistant Organisms And Patients' Risk Factors In The Intensive Care Unit Of King Fahad Hofuf Hospital, Saudi Arabia. International Journal of Health and Psychology Research, 2014; 2(1): 8-25.

Proksch, P, Ebel, R, Edrada, RA, Schuup, P, Lin, WH, Sudarsono, Wray, V, Steube, K. Detection of pharmacologically active natural products using ecology. Selected examples from Indopasific marine invertebrates and sponge-derived fungi. Pure and Appl Chem, 2003; 75(2): 343-352.

Sfanos K, Harmody D, Dang P, Ledger A, Pomponi S, McCarthy $\mathrm{P}$ and Lopez J. A molecular systematic survey of cultured microbial associates of deep-water marine invertebrates. Systematic and Applied Microbiology, 2005; 28(3): 242-264.

Shaikh S, Fatima J, Shakil S, Rizvi SMD, and Kamal MA. Prevalenve of multidrug resistant and extended spectrum beta-lactamase producing Pseudomonas aeruginosa in a tertiary care hospital. Saudi Journal of Biological Sciences, 2015; 2: 62-64.

World Health Organization. Evidence of hand hygiene to reduce transmission and infections by multidrug resistant organisms in healthcare settings. 2013, Genewa : WHO Press

World Health Organization. World Health Statistic 2013. Genewa : WHO Press

\section{How to cite this article:}

Handayani D, Murniati M, Rustini R. In Vitro Inhibitory Activity of Ethyl Acetat Extract of Symbiotic Bacteria Isolated from the Marine Sponge Haliclona fascigera against Multidrug Resistant Organism (MDRO). J App Pharm Sci, 2016; 6 (11): 218-222. 